\title{
FORMAÇÃO CONTINUADA COLABORATIVA DE PROFESSORES DE EDUCAÇÃO FÍSICA
}

\author{
Fábio Bernardo Bastos \\ Secretaria Municipal de Educação da Cidade do Rio de Janeiro, Rio de Janeiro, Rio de Janeiro, Brasil \\ Francis Natally Anacleto \\ Universidade Federal Rural do Rio de Janeiro, Rio de Janeiro, Rio de Janeiro, Brasil \\ José Henrique \\ Universidade Federal Rural do Rio de Janeiro, Rio de Janeiro, Rio de Janeiro, Brasil
}

\begin{abstract}
Resumo
O objetivo da pesquisa foi analisar o desenvolvimento de um projeto de formação continuada colaborativa considerando a natureza das interações interpessoais e sua repercussão em ações pedagógicas inovadoras desenvolvidas por professores de Educação Física. Trata-se de uma pesquisa qualitativa de caráter descritivo. A amostra foi composta por 13 professores de Educação Física da SME-RJ. O modelo de formação foi desenvolvido mediante a pesquisa-ação. Foram realizados oito seminários, sendo o último destinado à apresentação de projetos de intervenção pedagógica tematizados no uso de Tecnologias nas aulas de Educação Física. A análise evidenciou o valor da formação colaborativa, sendo observados processos de inovações e mudanças na prática pedagógica.
\end{abstract}

Palavras-chave: Desenvolvimento Profissional. Formação Colaborativa. Formação Continuada. Professor de Educação Física.

\section{Introdução}

O esforço de superação do desafio contemporâneo da educação brasileira, no sentido de assegurar a permanência bem-sucedida dos alunos nas escolas públicas, embora não livre de polêmica, tem sido evidente nas políticas educacionais que visam as reformas curriculares, a ampliação do ensino fundamental de oito para nove anos, nos sistemas avaliativos sistematizados em nível municipal, estadual e nacional, na criação do piso nacional na educação e nas políticas nacionais de formação continuada docente (BRASIL, 2005).

No Brasil, o trabalho precursor de Gatti (1997) merece destaque ao alertar para a necessidade de investimentos em ações de formação continuada que tenham como foco suprir as necessidades docentes. Para Ibiapina (2008), essas necessidades podem surgir a partir do contexto social que as originou, ou de um conjunto de aspirações formativas expressas pelos professores com o interesse de passar de um nível atual de conhecimento para outro superior.

A problemática da pesquisa parte do pressuposto de que as ações formativas de caráter continuado adotadas no Brasil se apresentam em uma perspectiva clássica, valendo-se de formações pontuais, breves e descontextualizadas da prática docente, levando o professor a participar do processo formativo apenas de "corpo presente" (FERREIRA; SANTOS; COS- 
TA, 2015). Estudos recentes, como os de Davis et al. (2011), Ferreira (2012) e Ferreira, Costa e Santos (2015) ratificam que a utilização destas estratégias é frequente e se fundamenta em modelos clássicos que nem sempre atendem às necessidades docentes. Além disso, a lógica que impõe a dicotomia entre o saber prático e o acadêmico, em que o fazer do professor é legitimado teoricamente por outrem, nem sempre considera as suas especificidades e necessidades.

Os programas de formação continuada devem ser estruturados a longo prazo, exigindo esforços sistemáticos e sustentáveis e a valorização da prática docente como um espaço privilegiado para a formação e reflexão sobre os modos de aprender e de ensinar. A formação continuada e a prática pedagógica são atividades convergentes, intercomunicativas, relacionadas ao cotidiano dos professores e das escolas, intervindo e sendo passível de intervenção, transformando e transformando-se, devendo implicar o docente num processo permanente e renovador de autoformação (PORTO, 2000; MACHADO, 2005). Este tipo de formação precisa estruturar processos que valorizem a sistematização dos saberes próprios, a capacidade para transformar a experiência em conhecimento e a formalização de um saber profissional de referência (PEREIRA; HENRIQUE, 2016).

Entretanto, a grande maioria dos programas de formação continuada contemporâneos se fundamenta na racionalidade técnica e visa o treinamento de habilidades comportamentais e de transmissão. Ainda, como agravante, o processo organizacional das instituições escolares pouco privilegia oportunidades de formação coletiva, nas quais os professores tenham a oportunidade de dialogar e encontrar soluções para os problemas cotidianos da escola e da sala de aula. A ideologia dominante coloca o professor como um indivíduo isolado, capaz de se autodeterminar de uma forma independente do contexto social. A proposição e a investigação de um projeto de formação colaborativa entre pares visam superar o modelo racional de formação inicial e continuada e suas consequências no desnivelamento das relações entre formador/mediador e professores, bem como a consequente individualização do processo formativo, característico nas modalidades tradicionais (FERREIRA; SANTOS; COSTA, 2015).

Segundo Vygotsky (1998), os ambientes formativos de caráter individualizado não oferecem grandes vantagens para a aprendizagem quando comparados às perspectivas de trabalho colaborativo. Chama a atenção para a forma como o aprendizado e os processos de pensamento transcorrem mediados pela palavra e na relação com outras pessoas, nos chamados processos interpsicológicos. O autor denomina como internalização o processo que implica na reconstrução interna de operações externas vinculadas à imitação ou cópia, na qual o sujeito desempenha um papel ativo e pode criar algo novo.

Neste sentido, a colaboração pode promover novas aprendizagens e a ressignificação de práticas docentes, visto que as interações realizadas nos níveis interpsicológicos e intrapsicológicos se tornam possíveis graças à contextualização da temática proposta, suas limitações, possibilidades de (re)construção e desenvolvimento de novos conhecimentos conectados com as necessidades de cada sujeito.

Quando o professor integra o saber pesquisado/compartilhado com a sua prática, interioriza outra lógica e o saber-fazer docente ganha mais significado. Em grupos de colaboração, os professores debatem sobre o progresso do processo, refletem criticamente o ensino, partilham uma linguagem para se referirem a conceitos, constroem e reconstroem juntos conhecimentos acerca do ensino, procedendo, desta forma, à autorregulação da sua aprendizagem e das suas práticas (MEINERZ, 2011).

A formação em contexto colaborativo necessita do compartilhamento das decisões por todos os envolvidos, que acabam por responsabilizarem-se pela produção conjunta, segundo suas necessidades, possibilidades e interesses. O compartilhamento de aprendizagens proporcionadas por ações colaborativas é consequência das experiências individuais que cada docen- 
te traz da sua história de vida, dos aspectos sociais e culturais dos seus cotidianos (LIBERALI et al., 2006; IBIAPINA, 2008).

O objetivo desta pesquisa foi analisar e descrever, a partir do desenvolvimento de um projeto de formação continuada colaborativa de professores de Educação Física, a atitude dos docentes frente a um processo alternativo de formação, elucidando o sentido por eles atribuído à participação e ao compartilhamento de experiências em busca da construção coletiva de conhecimentos, os efeitos percebidos para a sua formação pessoal e profissional, bem como os impactos no desenvolvimento de competências pedagógicas e metodológicas de ensino com potencial para proporcionar novos meios de aprendizagens aos discentes nas aulas de Educação Física.

\section{Metodologia}

Na busca de superação do modelo clássico de formação, a opção metodológica para o desenvolvimento desta pesquisa foi a pesquisa-ação em contexto colaborativo, em que os professores envolvidos são concebidos como autores e protagonistas da construção e reconstrução de suas práticas docentes cotidianas.

Thiollent (2008) percebe a pesquisa-ação como um tipo de pesquisa social com base empírica centrada diretamente numa situação ou num problema coletivo em que pesquisadores e professores estão envolvidos de modo participativo, assumindo juntos o controle da situação.

Para pesquisar colaborativamente, estudiosos e professores precisam se reunir para refletir sobre os conceitos que constituem as práticas adotadas pelos docentes e a teoria da qual deriva a crença na eficácia de tal prática a partir de ciclos reflexivos que promovam a análise, o diálogo e a colaboração entre pares com diferentes níveis de competência profissional.

A opção metodológica pela pesquisa-ação em contexto colaborativo se concretizou porque propôs que, de forma partilhada, os professores se comprometessem e compartilhassem experiências visando a transformação das suas práticas docentes, as quais estariam alicerçadas na reflexão na prática e sobre a prática. Uma proposta de formação compartilhada, reflexiva, emancipatória e colaborativa, na qual os professores se implicassem na mudança das práticas educativas ao longo do processo de formação e os motivasse a envolverem-se na concepção, realização e avaliação dos programas, consolidando redes de colaboração.

O método da pesquisa-ação colaborativa foi o que mais se adequou aos objetivos da pesquisa devido ao potencial em promover a participação ativa dos sujeitos, além da sua flexibilidade na construção coletiva de soluções para os desafios encontrados, visando compreender e transformar as práticas docentes (TRIPP, 2005; THIOLLENT, 2008; SILVA, 2011).

As estratégias de pesquisa perpassam pela utilização do método qualitativo. A pesquisa-ação possui cunho hermenêutico e fenomenológico, uma vez que os dados coletados e apresentados de forma predominantemente descritiva buscam valorizar o caráter interpretativo das subjetividades e intersubjetividades dos participantes no processo de formação e desenvolvimento profissional.

A amostra contou com o extrato de 13 docentes oriundos de um grupo de 51 professores de Educação Física lotados em escolas da área de abrangência das $4^{\mathrm{a}}$ e $11^{\mathrm{a}}$ Coordenadorias Regionais de Educação da Rede Municipal de Ensino do Rio de Janeiro, que participaram voluntariamente de encontros mensais de formação continuada na perspectiva colaborativa, na área de Educação Física.

A investigação transcorreu durante o ano letivo de 2013, por meio de oito seminários mensais. Os seminários foram conceptualizados de forma a estimular os professores ao protagonismo durante todo o processo de formação, de modo que, coletivamente, pudessem ensinar e aprender numa perspectiva de construção negociada e de abertura ao diálogo construti- 
vo, ético e crítico-reflexivo. Nos seminários, um professor e o pesquisador assumiram o papel de mediadores a fim de coordenar as condições técnicas, estruturais de cariz conceitual, didático e pedagógico, preservando o ambiente colaborativo para interação dos professores.

Quadro 1 - Estruturação e sistematização dos seminários de formação colaborativa

\begin{tabular}{|c|c|c|c|}
\hline Etapas & $\begin{array}{c}\text { Audiência } \\
\left(\mathbf{N}^{\circ} \text { Docentes }\right)\end{array}$ & Descrição dos Objetivos & $\begin{array}{c}\text { Instrumento Técnico de } \\
\text { Coleta de Dados }\end{array}$ \\
\hline Seminário I & 49 & $\begin{array}{l}\text { - Apresentação da proposta de formação colaborativa e } \\
\text { decisão sobre a adesão dos professores; } \\
\text { - Esclarecimentos sobre o ciclo da pesquisa-ação utili- } \\
\text { zada na pesquisa; } \\
\text { - Aplicação do questionário de competências. }\end{array}$ & Questionário \\
\hline Seminário II & 65 & $\begin{array}{l}\text { - Apresentação dos resultados do questionário de com- } \\
\text { petências; } \\
\text { - Decisão coletiva e eleição do tema em torno do qual } \\
\text { aconteceria o processo formativo; } \\
\text { - Discussões sobre experiências pregressas em relação } \\
\text { ao tema eleito para a formação. }\end{array}$ & Diário de Campo \\
\hline Seminário III & 49 & $\begin{array}{l}\text { - Debate sobre o texto 1: O contexto dos novos recur- } \\
\text { sos tecnológicos de informação e comunicação e a } \\
\text { escola (DUARTE; NEVES, 2008); } \\
\text { - Identificação dos meios tecnológicos viáveis nas au- } \\
\text { las de educação física; } \\
\text { - Formação de grupos para cada um dos meios tecno- } \\
\text { lógicos identificados; } \\
\text { - Discussões visando a elaboração de projetos de inter- } \\
\text { venção pedagógica na escola. }\end{array}$ & $\begin{array}{l}\text { - Registros em áudio e } \\
\text { vídeo, Transcrições e } \\
\text { análise de conteúdo; } \\
\text { - Diário de Campo. }\end{array}$ \\
\hline Seminário IV & 27 & $\begin{array}{l}\text { - Palestra com o tema: "O Professor Pesquisador"; } \\
\text { - Debate sobre Planejamento colaborativo; } \\
\text { - Discussões nos grupos com apresentações das possi- } \\
\text { bilidades de ações práticas. }\end{array}$ & $\begin{array}{l}\text { - Registros em áudio e } \\
\text { vídeo, Transcrições e } \\
\text { análise de conteúdo; } \\
\text { - Diário de Campo. }\end{array}$ \\
\hline Seminário V & 25 & $\begin{array}{l}\text { - Debate sobre o Texto } 2 \text { (específico para cada meio } \\
\text { tecnológico escolhido); } \\
\text { - Debate sobre as produções realizadas e eventuais } \\
\text { dificuldades, estratégias e experiências exitosas; } \\
\text { - Construção coletiva de projetos de utilização dos } \\
\text { meios tecnológicos nas aulas de educação física. }\end{array}$ & $\begin{array}{l}\text { - Registros em áudio e } \\
\text { vídeo, Transcrições e } \\
\text { análise de conteúdo; } \\
\text { - Diário de Campo. }\end{array}$ \\
\hline Seminário VI & 18 & $\begin{array}{l}\text { - Debate sobre o texto } 3 \text { (específico para cada meio } \\
\text { tecnológico escolhido); } \\
\text { - Apresentações voluntárias elou relato de experiências } \\
\text { sobre as intervenções práticas realizadas, com debates } \\
\text { sobre as dificuldades e propostas de superação; } \\
\text {-Discussões nos grupos com apresentações das possibi- } \\
\text { lidades de (re)significação das ações práticas. }\end{array}$ & $\begin{array}{l}\text { - Registros em áudio e } \\
\text { vídeo, Transcrições e } \\
\text { análise de conteúdo; } \\
\text { - Diário de Campo. }\end{array}$ \\
\hline Seminário VII & 26 & $\begin{array}{l}\text { - Debate sobre o texto } 4 \text { (específico para cada meio } \\
\text { tecnológico escolhido); } \\
\text { - Construção coletiva de projetos de utilização dos } \\
\text { meios tecnológicos nas aulas de educação física. }\end{array}$ & $\begin{array}{l}\text { - Registros em áudio e } \\
\text { vídeo, Transcrições e } \\
\text { análise de conteúdo; } \\
\text { - Diário de Campo. }\end{array}$ \\
\hline
\end{tabular}




\begin{tabular}{|c|c|c|c|}
\hline Seminário VIII & 19 & $\begin{array}{l}\text { - Apresentações das culminâncias dos projetos desen- } \\
\text { volvidos nas escolas; } \\
\text { - Avaliação sobre a experiência da Formação continua- } \\
\text { da colaborativa e as mudanças observadas nas práticas } \\
\text { docentes; } \\
\text { - Avaliação da Formação continuada colaborativa. }\end{array}$ & $\begin{array}{l}\text { - Registros em áudio } \\
\text { vídeo, Transcrições } \\
\text { análise de conteúdo; } \\
\text { - Diário de Campo. }\end{array}$ \\
\hline
\end{tabular}

O primeiro seminário constou do momento inicial de apresentação da proposta colaborativa e abrangeu discussões e decisões sobre a dinâmica da formação colaborativa, condições para o desenvolvimento das atividades e eleição do tema gerador associado às necessidades de formação dos professores.

Nesse sentido, inicialmente os professores discutiram a metodologia empregada, a qual enfatizou e valorizou os ciclos espiralados como eixo da pesquisa-ação colaborativa e princípio transversal em todo o processo formativo, a saber: a) Conscientização - identificação dos desafios que envolvem o trabalho docente; b) Planejamento - novas formas de entendimento pensadas e elaboradas a partir do processo de teorização das práticas, suscitando a busca de novas propostas curriculares, bem como novas estratégias pedagógicas; c) Ação com potencial de levar os envolvidos a novas formas de ação pedagógica; d) Registro das intervenções; e) Reflexão - constituição de um novo pensar sobre o processo, desencadeando um novo planejamento (TRIPP, 2005). Para garantir o processo de experimentação, foi acordado entre os professores que as ações de formação deveriam repercutir em projetos de intervenção pedagógica nas escolas de origem, visando (re)alimentar as reflexões coletivas e novas práticas.

A condição para o desenvolvimento das atividades de formação se alicerçou em três pilares: 1) a importância da frequência aos encontros; 2) a leitura antecipada dos textos enviados previamente aos encontros; e 3) a participação nos seminários de "espírito aberto" e cientes de que os pontos de vista, opiniões e questionamentos seriam sempre levados em consideração e respeitados.

A eleição do tema gerador foi conseguida mediante a aplicação do Questionário de Autoavaliação de Competências Pedagógicas em Educação Física (FERREIRA, 2012), com o objetivo de diagnosticar as necessidades de formação mais latentes no grupo, visando a eleição do tema a ser desenvolvido e/ou aprofundado nos seminários de formação.

No segundo seminário foi apresentado o tema em torno do qual se desenvolveria a formação colaborativa, em face da diagnose realizada no seminário anterior. Os resultados apontaram três áreas de competências pedagógicas em que os professores apresentaram menor índice de domínio: 1) Utilização de Tecnologias no Ensino; 2) Desenvolvimento de Processos Reflexivos; e 3) Ações e Atitudes de Cooperação. Coube aos professores elegerem a temática que seria contemplada ao longo da formação, tendo sido unânime a escolha do tema "Tecnologias no Ensino". Posteriormente, foram organizados grupos com cerca de cinco professores para discutirem possibilidades de realização de propostas pedagógicas que utilizassem as tecnologias nas aulas de Educação Física. Este momento serviu para os professores autodiagnosticarem seus conhecimentos sobre o tema, findando com a apresentação formal das sínteses coletivas sobre as possibilidades de intervenção baseadas no uso das tecnologias na educação física escolar.

No terceiro seminário os professores foram estimulados a sugerir meios tecnológicos que presumiam ser compatíveis com os conteúdos ministrados em suas aulas, de modo a não interferir ou causar interrupção no desenvolvimento curricular em curso nas escolas. Foram eleitos seis meios tecnológicos para construção e desenvolvimento dos projetos pedagógicos, sendo eles: Blog/Vlog, Games, Fotografia, Filmagem e Vídeo, Internet e Mix Tecnológico. Ainda nos subgrupos, os docentes foram estimulados a realizar debates acerca das experiên- 
cias teórico-práticas a serem desenvolvidas em suas aulas e, na sequência, convidados a compartilhar suas ideias com a plenária e discutir sugestões que acrescentassem à proposta.

Do quarto ao sétimo seminário, a dinâmica respeitou os princípios de espirais da pesquisa-ação, sempre envolvendo a teorização e o planejamento das atividades, a discussão e a reflexão coletiva, a prática pedagógica, o relato e a avaliação da ação pedagógica enfatizando a reflexão e evocando as duplas dialéticas: indivíduo-grupo e teoria-prática.

No que concerne ao processo de conceitualização teórica das discussões e elaboração de planos de intervenção pedagógica, os mediadores garantiram, previamente a cada encontro, a seleção e o envio de textos científicos/acadêmicos adaptados às temáticas de cada grupo. Concebeu-se que a teorização das discussões e reflexões permitiria superar processos dialógicos baseados exclusivamente no conhecimento tácito dos professores, além de proporcionar as condições para a busca de novas propostas metodológicas e estratégias de intervenção. A dinâmica de cada encontro contemplou dois momentos, sendo o primeiro de interações entre os membros dos subgrupos temáticos (microdinâmica); e o segundo de compartilhamento com todos os participantes dos aspectos mais relevantes acerca do planejamento e da significação das experiências socializadas (macrodinâmicas).

Os professores foram desafiados durante esses seminários a pensarem em alternativas que oferecessem o protagonismo aos alunos durante as experimentações práticas planejadas nos projetos pedagógicos, utilizando a tecnologia para dinamizar o desenvolvimento curricular.

O oitavo e último seminário representou o momento de culminância da formação colaborativa, sendo destinado às apresentações dos relatórios de intervenção pedagógica construídos colaborativamente pelos professores e desenvolvidos com a finalidade de compartilharem as possibilidades de uso dos meios tecnológicos nas aulas de Educação Física. Os relatórios foram feitos por escrito, além de contarem com o recurso de fotos e vídeos, gerando entre os pares momentos de avaliação e reflexão acerca das possibilidades pedagógicas de envolvimento e protagonismo dos alunos expressas nas experiências relatadas.

Ao final do último seminário foram realizadas entrevistas semiestruturadas retrospectivas, no formato de grupo de discussão (MEINERZ, 2011), no intuito de identificar as percepções dos envolvidos sobre a constituição do processo e as experiências na formação colaborativa.

Todos os diálogos nos seminários e nas entrevistas foram gravados em áudio. Quando da realização das atividades nos subgrupos (microdinâmicas) e durante a entrevista, todos os participantes se identificavam antes de prosseguir em seus diálogos. Os momentos de plenária (macrodinâmica) foram registrados em áudio e vídeo. Todos os registros em áudio foram transcritos e submetidos à análise de conteúdo para a interpretação dos resultados.

A pesquisa transcorreu conforme os procedimentos aprovados por Comitê de Ética na Pesquisa de uma instituição de ensino superior brasileira, com parecer emitido sob o protocolo $\mathrm{n}^{\circ} 23083.010180 / 2013-93$.

\section{Resultados E Discussão}

Durante todo o processo formativo buscou-se o comprometimento da formação com as necessidades reais dos professores, oferecendo espaços nos quais se sentissem à vontade e confiantes para apresentar propostas, colaborar uns com os outros, refletir e (re)construir novos caminhos e possibilidades para as práticas pedagógicas cotidianas e, acima de tudo, que fossem cúmplices das escolhas e decisões a serem tomadas em cada etapa. Tanto nos seminários quanto nas entrevistas retrospectivas, a maior parte dos professores externou depoimentos que denotam o sentimento de pertencimento ao grupo e a percepção de assunção do protagonismo no processo formativo. Neste sentido, conforme enunciado por Ibiapina (2008), os pro- 
fessores denotaram o entendimento de que o que estavam vivenciando em termos de formação continuada era diferente daquilo que já tinham experimentado em seu percurso profissional, seja relativamente à cumplicidade na condução do processo, seja na diversidade das possibilidades de exploração da tecnologia nos projetos de intervenção pedagógica ou pelo comprometimento dos professores com a proposta de formação colaborativa, como comprovam as falas dos professores em momentos diferentes da pesquisa.

Hoje em dia em termos de grupo nós acabamos nos colocando em outra posição, porque nós estamos fomentando um processo e não parados num lugar preocupados em tacar pedras, se a ideia estiver equivocada seremos todos cúmplices. (Seminário IV; Professor Giovani)

Eu acho que o bacana disso é que em todos esses meios tecnológicos, o que a gente pode fazer é explorar ao máximo todos os seus benefícios, como você colocou. Achei fantástico! Porque provavelmente ninguém aqui utilize esses meios tecnológicos iguais ao outro. De repente, como vocês do grupo de mix tecnológico falaram que cada grupo vai usar o meio de um jeito. O blog para Luciana vai funcionar de uma maneira e para o Robson de outra. (Seminário V; Professor Leandro)

Acho que as reuniões eram muito proveitosas, dificilmente você via professores saindo antes de terminar. Isso prova que o processo é colaborativo e estimulante. A gente ficava agarrada àquelas ações e problemas que nós levantamos. Essa é a grande chave do sucesso! Os assuntos eram levantados por nós e nós tentávamos resolver o problema. O grande lance está aí!. (Entrevista Retrospectiva Reflexiva - Grupo II; Professor Vitor)

Foi evidente a relação de envolvimento, apropriação e pertencimento dos professores com a proposta colaborativa. No primeiro depoimento, o Professor Giovani destaca o ineditismo da proposta para o grupo, rechaçando o imobilismo e assumindo cumplicidade e responsabilidade com as propostas construídas coletivamente. No segundo, o Professor Leandro percebe a possibilidade de diversificação da proposta dentro da realidade e possibilidades de utilização das tecnologias, incitando uma reflexão crítica na reunião restrita ao seu grupo. Já no terceiro, o Professor Vitor demonstra o envolvimento do grupo com a proposta, destacando o caráter crítico-emancipatório das ações e decisões planejadas e executadas pelos professores. Tais relatos reforçam e dialogam com os escritos de Meinerz (2011), que defendem a prática colaborativa como um processo autorregulatório das aprendizagens e das práticas docentes.

Os relatos dos professores levam a crer que a condução do processo de formação colaborativa, iluminado pela teoria, despertou nos professores, conforme estudos de Liberali et al. (2006), o senso de apropriação do espaço formativo, a partir das oportunidades de compartilhamento e construção crítica de conhecimentos; do processo de tomada de decisões acerca dos mecanismos e métodos de ensino e aprendizagem propostos entre pares; das negociações, discussões, reflexões e, em vista disso, das tensões na busca da compreensão das possibilidades de intervenção pedagógica.

As novas aprendizagens e a ressignificação das práticas foram comemoradas e valorizadas pelos professores e se tornaram possíveis por conta das interações realizadas nos níveis interpsicológicos e intrapsicológicos proporcionadas pela contextualização dos conhecimentos sobre o uso das tecnologias, observando as inovações praticadas, os percursos possíveis para o desenvolvimento dos novos conhecimentos nas aulas de educação física e conforme as condições estruturais e necessidades voltadas aos objetivos da intervenção docente durante a sua implementação. 
A formação continuada baseada nos pressupostos da colaboração permitiu aos professores a voz para compartilhar com seus pares as suas experiências, entendimentos, aceites e negações em relação às falas dos pares, que serviram de base para a desconstrução e reconstrução daquilo que cada um trazia e fazia. Entende-se, como assim sugere Bakhtin (2010), que os sujeitos respaldados na assimilação das aprendizagens pelas suas consciências durante as interações realizadas com os outros, passam a potencialmente articular signos.

Observou-se, também, a importância conferida pelos professores ao consequente desenvolvimento pessoal e profissional, conforme se percebe nos depoimentos seguintes, em que se constata a valorização das experiências compartilhadas com os pares, associadas a uma confiança crescente no desenvolvimento de propostas pedagógicas afins nas escolas.

O que mais contribuiu para mim foram essas trocas de experiências, principalmente na área tecnológica que sou crua. Já me arrisco a gravar e fotografar os alunos pelo incentivo que tive nas apresentações dos projetos no final. (Entrevista Retrospectiva Reflexiva II; Professora Cristiane)

Uma espécie de continuação daquilo que aprendi na Universidade [...] após aprovado em um concurso e de alguma maneira ter um espaço para dialogar sobre as práticas que vivenciamos na escola é muito bom. Esse momento foi organizado pelo Grupo de Trabalho. Trocarmos a nossa vivência na escola e aprimoramos a nossa prática diária. Eu penso que foi assim que aconteceu. (Entrevista Retrospectiva Reflexiva II; Professor Milton)

Durante o desenvolvimento da formação os professores remeteram-se aos problemas práticos encontrados na escola e às necessidades formativas dos alunos. No âmbito dos aspectos metodológicos do ensino, percebeu-se nos relatos colhidos durante as entrevistas retrospectivas uma maior preocupação com o protagonismo discente durante as aulas de educação física. Isso se confirmou, também, durante as apresentações dos projetos desenvolvidos pelos professores nas escolas. Assim, a colaboração proporcionou aos participantes a mobilização de ideias, valores, desejos e experiências para os debates no grupo e que, pela sua diversidade, apresentam uma relação de assimetria de conhecimentos benéfica ao processo de (re)construção de novos saberes. Corroborando com Liberali et al. (2006), é fundamental na proposta colaborativa que os professores tenham chances iguais de apresentarem e de negociarem os sentidos e valores que servem de embasamento ao entendimento da realidade e das suas escolhas, além de compreenderem as interpretações do outro.

No que diz respeito à articulação entre teoria e prática, apesar da percepção dos professores sobre o contributo das leituras para as reflexões coletivas e concepção dos projetos pedagógicos, o desenvolvimento da pesquisa deixou perceber que os leitores de parte ou totalidade dos textos ainda foram minoria no grupo investigado. Foi evidente o consenso entre os participantes sobre a importância da teorização para o desenvolvimento das propostas pedagógicas, entretanto também se mostraram evidentes as dificuldades de grande parte dos professores em concretizarem esse processo, como se denota evidente no estudo de González e Borges (2015). Entre as justificativas apresentadas aparece o esgotamento físico provocado pela sobrecarga de trabalho, a falta de objetivação dos horários destinados aos períodos complementares nas escolas - utilizados na maioria das vezes para lançamento de notas e questões burocráticas; e ausência do hábito de leituras. Tal fato denota a necessidade de diversificar as estratégias utilizadas para fomentar a contextualização teórica da formação colaborativa, seja através de envio de textos pré-encontros, de apresentações teóricas por um professor do grupo para o próprio grupo, rodas de conversa com especialistas, leitura realizada no encontro, entre outras estratégias que possibilitem aos professores equilibrar os subsídios da teoria e os saberes tácitos provenientes da prática. Afinal, conhecer o fenômeno da prática docente significa 
um esforço teórico para modificá-lo, tendo como base a experiência profissional (ALARC $\tilde{A} O, 2011$ ).

Na perspectiva dos professores, o espaço de formação proporcionou um ambiente favorável às mudanças e/ou (re)construção das práticas docentes, seja na fala do Professor Roberto, ao valorizar o ineditismo da proposta de formação em sua trajetória docente, ou valorizando o que o outro trazia para o compartilhamento pedagógico, conforme exposto pelo Professor Alex.

Eu acho que fez com que fossem mais interessantes os encontros, pelo menos da minha parte [...] o que estava sendo feito era novo, estava sendo a construção de uma coisa que poderia ser utilizado por nós futuramente, espero que o quanto antes. (Entrevista Retrospectiva Reflexiva II; Professor Roberto)

Eu acho que a proposta é muito boa e enfatiza a troca. A gente não fica só unilateral, de chegar e ver uma pessoa expor. A proposta traz essa coisa da troca e cada um tem a sua vivência dentro da sua escola. Até onde pude acompanhar, apesar de todo processo ser dinâmico. Ela vai tomando forma ao longo dos encontros [...]. (Entrevista Retrospectiva Reflexiva II; Professor Alex)

O Professor Leandro sintetizou o processo construtivo e de mudança fundamentado na proposta de formação colaborativa, elencando aspectos que implicaram nas práticas dos professores relacionadas à valorização da opinião do outro, à confiança entre os pares para a colaboração, exposição das dificuldades e questionamentos sobre os dilemas do cotidiano docente e às soluções propostas pelos colegas.

Eu acho que é justamente neste processo de "deixar o outro falar e colocar para fora o que está sentindo", que é a base desse percurso, é que a gente constrói realmente a confiança [...] que exponham seus problemas, porque ele sente que é um espaço que ele faz parte. Por muito tempo a gente fica, na nossa profissão tolhida da oportunidade de falar. Onde a sua opinião é confrontada com a opinião de outras pessoas. Isto é outra coisa bacana que acontece nesse processo que acho muito legal. Vamos vendo através das trocas o que o colega faz, como é que ele consegue resolver os problemas, para onde a gente pode avançar. É um momento bacana de aprender com o outro e se sentir parte efetiva daquele negócio. (Entrevista Retrospectiva Reflexiva III; Professor Leandro)

Para que os professores se sintam à vontade e confiantes para realizarem o processo de socialização de modo a fomentar as práticas dialógicas, ressignificação de práticas docentes e novos aprendizados, é necessário um período de ajustamento entre os envolvidos na atividade formativa. Uma postura defensiva por parte dos professores pode impedir o compartilhamento do objeto do discurso por parte dos interlocutores, gerando a omissão das palavras e ideias e, assim, dificultando a fluidez das discussões, a complementação e a adjetivação das propostas por parte dos participantes na formação colaborativa, conforme realçado por Bossle, Molina Neto e Wittizorecki (2013).

As iniciativas colaborativas surtiram efeito a cada encontro, com os professores sentindo-se cada vez mais apoiados e confiantes, confirmando a importância do outro no processo de ascensão às funções psíquicas superiores difundidas por Vygotsky (1998), utilizando-se da mediação da linguagem, (re)aprendendo e desenvolvendo-se em um modelo dialógico. Este autor evoca o conceito da Zona de Desenvolvimento Proximal (ZDP) para exemplificar as possibilidades de aprendizagem a partir do contato com o outro, reforçado pelo que Bakhtin (1986) considera inicialmente como imitação dos processos de desenvolvimento e aprendizagem por parte dos professores, para depois adaptá-los às suas necessidades, anseios e rea- 
lidade. Os professores afirmaram ter tido a oportunidade de ressignificar práticas, perceber novas possibilidades de aplicação dos conteúdos nas aulas de educação física, bem como motivar os alunos a participarem ativamente do processo de ensino e aprendizagem a partir da utilização dos meios tecnológicos.

A experiência de formação continuada colaborativa culminou com a apresentação de projetos tecnológicos planejados coletivamente nos seminários e concretizados pelos professores nas escolas. Os projetos apresentados versaram sobre o uso de games, filmagem/vídeo, fotografia, Blog/Vlog e internet, aplicados às aulas de Educação Física. As apresentações dos projetos denotaram ser possível o desenvolvimento de conteúdos inovadores na disciplina e, consequentemente, as possibilidades de aprendizagem dos alunos mediadas pelos meios tecnológicos nas aulas de Educação Física. Infelizmente, a greve realizada pelos professores da Rede Municipal de Ensino do Rio de Janeiro no ano de 2013 se constituiu como um dos motivos que inviabilizou o desenvolvimento e a apresentação dos projetos pedagógicos para um quantitativo maior de professores.

Entendemos que os professores, ao longo do processo formativo, puderam observar, escutar e prestar atenção nas experiências compartilhadas com os seus pares, (re)construindo em sua própria realidade o que perceberam como essencial nas descrições e práticas do outro, experimentando e produzindo um novo produto que pôde ser comparado com o original. Assim, as evidências apresentadas nos resultados desta pesquisa são relevantes para afirmar a importância de propostas formativas desta natureza para o aprimoramento e a inovação das práticas pedagógicas docentes, bem como para o desenvolvimento profissional dos professores.

\section{Considerações Finais}

Em resposta aos objetivos desta pesquisa foi possível constatar um consenso entre os professores no sentido da valorização da formação colaborativa como espaço de construção de saberes que transita dialeticamente entre o individual e o coletivo.

Constatou-se que a concepção de uso das tecnologias nas aulas de Educação Física representava grande desafio para os professores pela dificuldade em pensar e operar pedagogicamente os meios tecnológicos e vislumbrar sua utilização nas aulas de Educação Física. Contudo, o compartilhamento de saberes entre os pares despertou um universo de possibilidades de aplicação nas aulas.

$\mathrm{O}$ aspecto mais valorizado pelos professores foi a oportunidade de trocar experiências entre pares, processo intimamente associado à construção coletiva do conhecimento. As ações que envolveram o planejamento e a reflexão foram referidas como momentos ricos da formação pelo fato de permitirem o compartilhamento de saberes e suporte para as decisões na elaboração dos projetos de ensino. Os debates sobre alternativas e estratégias de atuação pedagógica, a construção de práticas em conteúdos antes desconhecidos e o suporte mútuo em apoio à construção de propostas de intervenção se mostram significativos durante a formação colaborativa.

A construção desta proposta de formação colaborativa permitiu a identificação de aspectos que deverão ser levados em consideração por pesquisadores ou órgãos envolvidos em ações de formação continuada que vislumbrem o desenvolvimento de propostas similares, nomeadamente aqueles relacionados aos cuidados acerca do quantitativo de professores envolvidos nas atividades, sob o risco de não vencer a etapa de socialização e confiança, tão significativas para a partilha entre pares. Ainda, buscar a diversificação de estratégias para a teorização das práticas docentes antes, durante e depois das sessões colaborativas, como um legado que acompanhará o professor na busca de caminhos e soluções para as questões que surgem cotidianamente nas aulas. 
Enfim, a concepção de formação continuada colaborativa estruturada e proposta nesta investigação pode ser um caminho para o desenvolvimento de pesquisas que empoderam o professor como protagonista no processo de construção do conhecimento, motivando um mergulho profundo no objeto de estudo e seus fenômenos contextuais. Também ressalta-se o desafio proposto no design desta investigação, fundamentada metodologicamente na perspectiva da pesquisa-ação, por permitir enxergar o potencial gerador de conhecimento da colaboração ao mesmo tempo em que demonstra em que a proposta precisa ser ajustada, melhorada e modificada para atender as necessidades reais, de professores reais, em escolas reais, com alunos reais.

\title{
COLLABORATIVE CONTINUING EDUCATION OF PHYSICAL EDUCATION TEACHERS
}

\begin{abstract}
The objective of the research was to analyze the development of a collaborative continuing education project considering the nature of interpersonal interactions and its repercussion on innovative pedagogical actions developed by Physical Education teachers. This is a descriptive qualitative research. The sample consisted of 13 Physical Education teachers from SMERJ. The training model was developed through action research. Eight seminars were held, the last one being aimed at the presentation of pedagogical intervention projects, thematized in the use of Technologies in Physical Education classes. The analysis evidenced the value of collaborative training, observing processes in the innovations and changes in pedagogical practice.
\end{abstract}

Keywords: Professional Development. Collaborative Training. Continuing Education. Physical Education Teacher.

\section{FORMACIÓN CONTINUA COLABORATIVA DE PROFESORES DE EDUCACIÓN FÍSICA}

\section{Resumen}

El objetivo de la investigación fue analizar el desarrollo de un proyecto de formación continuada colaborativa considerando la naturaleza de las interacciones interpersonales y su repercusión en acciones pedagógicas innovadoras desarrolladas por profesores de Educación Física. Se trata de una investigación cualitativa de carácter descriptivo. La muestra fue compuesta por 13 profesores de Educación Física de la SME-RJ. El modelo de formación fue desarrollado mediante la investigación-acción. Se realizaron ocho seminarios, siendo el último destinado a la presentación de proyectos de intervención pedagógica tematizados en el uso de Tecnologías en las clases de Educación Física. El análisis evidenció el valor de la formación colaborativa, siendo observados procesos de innovaciones y cambios en la práctica pedagógica.

Palabras clave: Desarrollo Profesional. Colaboración. Educación Continua. Educación Física.

\section{Referências}

ALARCÃO, I. Professores reflexivos em uma escola reflexiva. 8. ed. São Paulo: Cortez, 2011. 
BAKHTIN, M. M. Para uma filosofia do ato responsável. São Carlos: Pedro \& João Editores, 2010

BAKHTIN, M. M. Speech Genres and Other Late Essays. Austin: University of Texas Press, 1986.

BOSSLE, F.; MOLINA NETO, V.; WITTIZORECKI, E. S. Trabalho docente coletivo na educação física escolar. Pensar a Prática, Goiânia, v. 16, n. 2, p. 401-415, abr./jun. 2013.

BRASIL. Ministério da Educação. Rede Nacional de Formação Continuada de Professores de Educação Básica - Orientações gerais. Distrito Federal: MEC, 2005.

DAVIS, C. L. F. et al. Formação continuada de professores em alguns estados e municípios do Brasil. Caderno de Pesquisa, São Paulo, v. 41, n. 144, p. 826-849, set./dez. 2011.

FERREIRA, J. da S. Perfil de formação continuada e autoavaliação de competências docentes na educação física escolar. 2012. 117 f. Dissertação (Mestrado em Educação) - Programa de Pós-graduação em Educação, Contextos Contemporâneos e Demandas Populares, Universidade Federal Rural do Rio de Janeiro, Rio de Janeiro, 2012.

FERREIRA, J. da S.; SANTOS, J. H.; COSTA, B. de O. Perfil de formação continuada de professores de Educação Física: modelos, modalidades e contributos para a prática pedagógica. Revista Brasileira Ciências do Esporte, Porto Alegre, v. 37, n. 3, p. 289-298, ago./set. 2015 .

GATTI, B. A. Formação de professores e carreira: problemas e movimentos de renovação. Campinas, SP: Editora Autores Associados, 1997.

GONZÁLEZ, F. J.; BORGES, R. M. Diálogos sobre o ensino dos esportes na Educação Física escolar: uma pesquisa-ação na formação continuada. Revista Motrivivência, Florianópolis, v. 27, n. 45, p. 172-188, set. 2015. Disponível em: $<$ https://periodicos.ufsc.br/index.php/motrivivencia/article/view/21758042.2015v27n45p172/30203>. Acesso em: 06 jan. 2018.

IBIAPINA, I. M. L. M. Pesquisa Colaborativa: Investigação, Formação e Produção de Conhecimentos. Brasília: Liber Livro, 2008. v. 17. (Série Pesquisa).

LIBERALI, F. C. et al. Educando para a cidadania em contextos de transformação. the ESPecialist, São Paulo, v. 27, n. 2, p. 169-188, jan. 2006.

MACHADO, M. A. de J. A avaliação docente como processo de formação contínua em serviço. 2005. 130 f. Dissertação (Mestrado em Educação) - Faculdade de Educação, Pontifícia Universidade Católica de São Paulo, São Paulo, 2005.

MEINERZ, C. B. Grupos de Discussão: uma opção metodológica na pesquisa em educação. Educação e Realidade, Porto Alegre, v. 36, n. 2, p. 485-504, maio/ago. 2011.

PEREIRA, S. A. M.; HENRIQUE, J. A formação inicial na licenciatura em educação física: a prática como núcleo de formação e de unidade teoria-prática. In: HENRIQUE, J; ANACLETO, F. N. A.; PEREIRA, S. A. M. (Org.). Desenvolvimento Profissional de Professores de Educação Física. Curitiba: CRV, 2016. p. 45-70. 
PORTO, Y. da S. Formação continuada: a prática pedagógica recorrente. In: MARIN, Alda Junqueira. (Org.). Educação continuada: reflexões, alternativa. Campinas, SP: Papirus, 2000. p. 11-37.

SILVA, M. L. C. A Investigação-acção em contexto colaborativo: mudanças nas concepções e práticas dos professores. 2011. 318 f. Tese (Doutorado em Educação) - Instituto de Educação, Universidade de Lisboa, 2011.

THIOLLENT, M. Metodologia da pesquisa-ação. 14. ed. São Paulo: Cortez, 2008. TRIPP, D. Pesquisa-Ação: Uma introdução metodológica. Educação e Pesquisa, São Paulo, v. 31, n. 3, p. 443-466, set./dez. 2005.

VYGOTSKY. L. S. A formação social da mente. São Paulo: Martins Fontes, 1998.

Recebido em: $14 / 05 / 2017$

Revisado em: 23/08/2017

Aprovado em: 26/01/2018

Endereço para correspondência:

francisnatally@yahoo.com.br

Francis Natally Anacleto

Universidade Federal Rural do Rio de Janeiro

Rodovia BR 465 - Km 7

Rio de Janeiro - RJ 